\title{
A functional SNP in the NKX2.5-binding site of ITPR3 promoter is associated with susceptibility to systemic lupus erythematosus in Japanese population
}

\author{
Tetsuya Oishi $\cdot$ Aritoshi Iida $\cdot$ Shigeru Otsubo $\cdot$ Yoichiro Kamatani $\cdot$ Masayuki Usami $\cdot$ Takashi Takei \\ Keiko Uchida · Ken Tsuchiya · Susumu Saito · Yozo Ohnisi · Katsushi Tokunaga · Kosaku Nitta • \\ Yasushi Kawaguchi · Naoyuki Kamatani · Yuta Kochi · Kenichi Shimane $\cdot$ Kazuhiko Yamamoto • \\ Yusuke Nakamura · Wako Yumura · Koichi Matsuda
}

Received: 29 October 2007/ Accepted: 17 November 2007/Published online: 25 January 2008

(C) The Japan Society of Human Genetics and Springer 2008

\begin{abstract}
Systemic lupus erythematosus (SLE) is one of the common autoimmune diseases with complex genetic components. To identify a gene(s) susceptible to SLE, we performed a case-control association study using genomewide gene-based single nucleotide polymorphisms (SNPs) in Japanese population. Here we report that an SNP (rs3748079) located in a promoter region of the inositol
\end{abstract}

Electronic supplementary material The online version of this article (doi:10.1007/s10038-007-0233-3) contains supplementary material, which is available to authorized users.

T. Oishi $\cdot$ S. Otsubo · Y. Kamatani · M. Usami · Y. Ohnisi · Y. Nakamura · K. Matsuda $(\bowtie)$

Laboratory of Molecular Medicine, Human Genome Center, Institute of Medical Science, the University of Tokyo,

4-6-1 Shirokanedai, Minato, Tokyo 108-8639, Japan

e-mail: koichima@ims.u-tokyo.ac.jp

T. Oishi $\cdot$ S. Otsubo $\cdot$ T. Takei $\cdot$ K. Uchida $\cdot$ K. Tsuchiya $\cdot$

K. Nitta · W. Yumura

Department of Medicine, Kidney Center, Tokyo Women's

Medical University, Tokyo 162-8666, Japan

A. Iida $\cdot$ S. Saito

Laboratory for Genotyping, SNP Research Center,

The Institute of Physical and Chemical Research (RIKEN),

Kanagawa 230-0045, Japan

K. Tokunaga

Department of Human Genetics, Graduate School of Medicine, University of Tokyo, Tokyo 108-8639, Japan

Y. Kawaguchi · N. Kamatani

Institute of Rheumatology, Tokyo Women's Medical University,

Tokyo 162-8666, Japan

Y. Kochi $\cdot$ K. Shimane $\cdot$ K. Yamamoto

Laboratory for Rheumatic Diseases, SNP Research Center,

The Institute of Physical and Chemical Research (RIKEN),

Kanagawa 230-0045, Japan 1,4,5-triphosphate receptor type 3 (ITPR3) gene on chromosome 6p21 was significantly associated with SLE in two independent Japanese case-control samples $[P=$ 0.0000000178 with odds ratio of $1.88,95 \%$ confidence interval (CI) of 1.51-2.35]. This particular SNP also revealed associations with rheumatoid arthritis (RA) ( $P=0.0084$ with odds ratio of $1.23,95 \% \mathrm{CI}$ of $1.05-1.43$ ) and with Graves' disease (GD) $(P=0.00036$ with odds ratio of $1.57,95 \% \mathrm{CI}$ of $1.22-2.02)$. We found the binding of NKX2.5 specific to the non-susceptible $\mathrm{T}$ allele in the region including this SNP. Furthermore, an SNP in NKX2.5 also revealed an association with $\operatorname{SLE}(P=0.0037$ with odds ratio of $1.74,95 \% \mathrm{CI}$ of $1.19-2.55)$. Individuals with risk genotype of both ITPR3 and NKX2.5 loci have higher risk for SLE (odds ratio $=5.77$ ). Our data demonstrate that genetic and functional interactions of ITPR 3 and NKX2.5 play a crucial role in the pathogenesis of SLE.

Keywords SLE - Genome wide association study · SNP · ITPR3 - NKX2.5

\section{Introduction}

Systemic lupus erythematosus (OMIM \#152700) is one of the common autoimmune diseases that predominantly afflict women of child-bearing age. The clinical features and serological abnormalities observed in patients with SLE are remarkably diverse and make clinical assessment and treatment very difficult. Anti-inflammatory drugs and immunosuppressive drugs such as cortisone, azathioprine, methotrexate, and cyclophosphamide have been widely used for treatment of this disease and contribute to significant improvement in prognosis of patients with SLE; although the 4-year survival was estimated to be $\approx 50 \%$ in 
the 1950s (Merrell and Shulman 1955), the 15-year survival rate is at present estimated to be approximately $80 \%$. Despite the improved prognosis in the majority of SLE patients, a significant proportion of the patients still suffer from the disease and/or severe adverse reactions caused by these drugs. For example, synthetic glucocorticoid causes adverse events including hypertension, hyperglycemia, diabetes, cataract, glaucoma, infection, psychosis, osteoporosis, and osteonecrosis. To improve quality of life for the SLE patients, one of the critical steps is to elucidate the molecular mechanism causing SLE.

Systemic lupus erythematosus is characterized by autoantibodies against nuclear, cytoplasmic, and cell surface molecules that transcend organ-specific boundaries. An impaired cellular and humoral immune response caused by hyperactivation of $\mathrm{T}$ and $\mathrm{B}$ lymphocytes has been considered to be one of critical molecular mechanisms of this disease (Shanks et al. 1999; Sternberg et al. 1992; Wick et al. 1993; Wilder 1996). Tissue deposition of antibodies or immune complex induces inflammation and subsequent injury of multiple organs and finally results in clinical manifestations of SLE, including glomerulonephritis, dermatitis, thrombosis, vasculitis, seizures and arthritis. In addition, recent accumulated evidence strongly suggests involvement of genetic components associated with SLE susceptibility (Deapen et al. 1992; Gaffney et al. 2000; Tsao 2004; Vyse and Kotzin 1998). Monozygous twins show a higher concordance rate of this disease (24$58 \%$ ) than dizygous twins (2-5\%), and the family history of SLE significantly increases the risk of SLE (Tsao 2003). Genetic susceptibility to SLE is inherited as a complex trait, and seven loci (chromosome 1q23, 1q25-31, 1q41-42, 2q35-37, 4p16-15.2, 6p11-21, and 16q12) have been revealed to be the significant linkage to SLE in several genome-wide linkage studies (Tsao 2004).

Linkage disequilibrium (LD) mapping on the basis of whole-genome SNP screening is now widely used as a powerful approach to identify genes associated with various diseases. We have been performing a genome-wide case-control association study in a Japanese population and successfully identified several genes associated with myocardial infarction, rheumatoid arthritis, osteoarthritis, Crohn's disease and brain infarction (Hata et al. 2007; Kizawa et al. 2005; Kubo et al. 2007; Ozaki et al. 2006; Suzuki et al. 2003; Yamazaki et al. 2005).

We here report identification of significant association of a functional SNP on ITPR3 gene with SLE. We also demonstrate the specific binding of NKX2.5 to the nonsusceptible allele in the region corresponding to this functional SNP as well as an association of an SNP in NKX2.5 with SLE. ITPR3 is an intracellular $\mathrm{Ca}^{2+}$ release channel that mediates $\mathrm{Ca}^{2+}$ mobilization in response to the binding of a second messenger, inositol 1,4,5-trisphosphate
(Patterson et al. 2004), and recent studies have indicated that ITPR3 plays a crucial role in the regulation of apoptosis signaling in T lymphocytes (Blackshaw et al. 2000; Hanson et al. 2004; Mendes et al. 2005). Hence, our data indicating that genetic variants of ITPR3 and NKX2.5 influence risk of SLE should offer a novel insight into the pathogenesis of SLE.

\section{Methods}

Subjects

A total of 178 individuals (case1 and 2) with SLE (89.7\% women; mean \pm SD $31.3 \pm 13.0$ years) were diagnosed at Tokyo Women's Medical University. A second cohort of SLE patients (case $3, n=365,93.6 \%$ women; mean \pm SD $31.6 \pm 11.6$ years) was recruited for the study through several medical institutes in Japan. All patients were diagnosed according to the criteria of the American College of Rheumatology for classification of Systemic Lupus Erythematosus (Hochberg 1997). Four independent cohorts of unaffected control subjects $(n=535,361,981$, and 719 for control 1-4, respectively) were recruited through several medical institutes in Japan. We obtained informed consent from each subject as approved by the ethical committee at the Institute of Medical Sciences, University of Tokyo, and also that at Tokyo Women's Medical University and each medical institute. We extracted genomic DNA from peripheral blood leukocytes of SLE patients and control subjects using standard protocols.

Patients with RA ( $n=1,122,78.9 \%$ women; mean \pm SD $59.4 \pm 12.3$ years $)$ and Graves' disease $(n=373$, $72.1 \%$ women; mean $\pm \mathrm{SD} 44.8 \pm 13.9$ years) were enrolled for the study through the Biobank Japan in the Institute of Medical Sciences, University of Tokyo. Rheumatoid arthritis patients were diagnosed according to the criteria of the American College of Rheumatology for RA (Arnett et al. 1988). Diagnosis of Graves' disease was established based on clinical findings as well as results of routine examinations for circulating thyroid hormone and thyroid-stimulating hormone (TSH) concentrations, serum levels of antibodies against thyroglobulin, thyroid microsomes and TSH receptors, ultrasonography, ${ }^{[99 \mathrm{~m}]} \mathrm{TcO}_{4}^{-}$or $\left[{ }^{123} \mathrm{I}\right]$ uptake, and also thyroid scintigraphy.

A large-scale association study

For the association study, we used the JSNP database and carried out SNP genotyping as described previously (Kochi et al. 2005; Seki et al. 2005; Tokuhiro et al. 2003; Tsunoda et al. 2004). First, we attempted genotyping of 
52,608 SNP loci using genomic DNAs from 94 patients with SLE and 535 control individuals. We successfully genotyped 50,464 SNP loci and calculated $P$ values for each SNP locus as described previously (Kochi et al. 2005; Tokuhiro et al. 2003). One thousand three hundred and ten SNPs that showed a $P$ value of 0.01 or smaller at the first screening were further genotyped using DNAs from 84 additional SLE subjects and another 361 control subjects. For a fine-scale association study of the ITPR3 gene, we further screened SNPs in the region by direct sequencing of genomic DNA from 16 affected individuals as described previously (Kochi et al. 2005; Seki et al. 2005; Tokuhiro et al. 2003). We genotyped these SNPs using the Invader assay combined with multiplex-PCR using ABI7700 and 7900 (Applied Biosystems) and tested for association (Ohnishi et al. 2001; Seki et al. 2005). Typing for $H L A-D R B 1$ and $H L A-B$ genes was performed using commercial typing kits (WAK Flow, Wakunaga, Hiroshima, Japan), which are based on PCR-sequence specific oligonucleotide probing coupled with Luminex multiple analyte profiling technology as described previously (Han et al. 2003).

\section{Luciferase assay}

We generated by PCR amplification eight tandem-copies of oligonucleotides corresponding to nt -1015 to -999 of ITPR3 that contained the candidate functional SNP and cloned into pGL3-Promoter vector (Promega, Madison, WI) upstream of the SV40 promoter. PCR primers or oligonucleotides used for vector construction were described in Supplementary Table 5. Jurkat (acute $\mathrm{T}$ cell leukemia) cell line was purchased from ATCC, and HEK293T cell line was obtained from Riken Cell Bank. All cells were cultured under conditions recommended by their respective depositors. Jurkat cells were transfected with $500 \mathrm{ng}$ of reporter plasmid with $50 \mathrm{ng}$ of the pRL-CMV Renilla luciferase vector (Promega, Madison, WI) as an internal control for transfection efficiency by using $3 \mu \mathrm{l}$ of DMRIE$C$ reagent (Invitrogen, Carlsbad, CA). HEK 293T cells were transfected with $500 \mathrm{ng}$ of either one of the constructs and $50 \mathrm{ng}$ of the pRL-TK Renilla luciferase vector (Promega, Madison, WI) as an internal control for transfection efficiency by using $1.5 \mu$ of FuGENE 6 Transfection reagent (Roche, Basel, Switzerland). Moreover, Jurkat cells were co-transfected with $250 \mathrm{ng}$ of the eight-tandem-copy construct, $25 \mathrm{ng}$ of the pRL-CMV vector and NKX2.5 expression vector by using $3 \mu \mathrm{l}$ of DMRIE-C reagent (Invitrogen, Carlsbad, CA). At $48 \mathrm{~h}$ after the transfection, the cells were solubilized, and the luciferase activity was measured using the Pikkagene dual luciferase assay system (Tokyo Inc., Tokyo, Japan).

\section{EMSA}

We prepared nuclear extracts from Jurkat cells and HEK293T cells as previously described (Hata et al. 2007). We stored nuclear extracts in aliquots at $-80^{\circ} \mathrm{C}$ until their use. Protein concentration was measured by the Bio-Rad Dc Protein Assay (Bio-Rad Laboratories, Inc., Richmond, CA) with bovine serum albumin as standard. We incubated the nuclear extract with 17-bp double-strand oligonucleotides corresponding to each of the $-1009 \mathrm{C}$ and $-1009 \mathrm{~T}$ alleles for $30 \mathrm{~min}$ at room temperature. Oligonucleotide sequences are listed in Supplementary Table 5. Probes were labeled using T4 polynucleotide kinase (TOYOBO, Osaka, Japan). For competition studies, we pre-incubated the nuclear extract with unlabeled oligonucleotides (50- or 100-fold excess) before adding labeled oligonucleotide. For the supershift assay, we incubated protein-DNA complex with $1 \mu \mathrm{g}$ of antibody to HA for $15 \mathrm{~min}$ before electrophoresis. Protein-DNA complexes were separated by electrophoresis on a $4 \%$ polyacrylamide gel in $0.5 \times$ TBE buffer. The gels were dried on $3 \mathrm{MM}$ Wattman paper and exposed for autoradiography at $-80^{\circ} \mathrm{C}$ for several hours.

\section{ChIP assay}

ChIP assay was performed using a ChIP assay kit (Upstate Biotechnology, Waltham, MA) in accordance with the manufacturer's recommendations. HEK293T cells were transfected with pCAGGS/HA-NKX2.5 or pCAGGS (mock) vector. We cross-linked HEK293T cells with $1 \%$ formaldehyde for $10 \mathrm{~min}$ and then subjected DNA-protein complex to immunoprecipitation with antibodies to HA (Roche, Basel, Switzerland) or Flag (Sigma, St Louis, MO). The primers used for PCR amplifications are listed in Supplementary Table 5.

\section{Real time PCR}

We analyzed DNA sequence of SNP rs3748079 locus of several cell lines and identified that HEK293T, HepG2 and A549 had homo-, hemi- or heterozygous with non-susuceptible T allele. H1299, Hela and SBC5 cells were shown to have homo (or hemi) zygous with the susuceptible $\mathrm{C}$ allele. These cell lines were transfected with $10 \mu \mathrm{g}$ of the NKX2.5 expression vector. We harvested the cells at 0,12 and $24 \mathrm{~h}$ after transfection, and extracted total RNA from the cells and synthesized first-strand cDNA using superscript II reverse transcriptase (Invitrogen, Carlsbad, CA). We carried out real-time quantitative PCR on ABI PRISM 7700 (Applied Biosystems, Foster City, CA) using the SYBR Premix Ex Taq (TaKaRa, Tokyo, Japan) according to the manufacturer's instructions. First-strand cDNA was 
amplified using primers specific for ITPR3 or beta 2 microglobulin (B2M) genes. Copy numbers of ITPR 3 were calculated by referring standard curves and normalized by using $B 2 M$ as an internal control. Specific primer sequences are listed in Supplementary Table 5.

Dexamethasone treatment with human peripheral blood mononuclear cells (PBMC)

Dexamethasone in powder form was purchased from Sigma (St Louis, MO). The blood obtained from healthy donors with informed consent was centrifuged through Lymphoprep Tube (AXIS-SHIELD, Dundee, UK), and human peripheral blood mononuclear cells (PBMCs) accumulated at the interface were washed with PBS. Fresh PBMCs were resuspended at a concentration of $1 \times 10^{6}$ cells $/ \mathrm{ml}$ in RPMI 1640 medium with penicillin and $10 \%$ fetal bovine serum. The cells were incubated in the presence of dexamethasone $(10 \mathrm{nM})$ for 24 or $48 \mathrm{~h}$. We extracted total RNA from PBMC and synthesized first-strand cDNA. We carried out real-time quantitative PCR on ABI PRISM 7700 (Applied Biosystems, Foster City, CA) using the SYBR Premix Ex Taq (TaKaRa, Tokyo, Japan) according to the manufacturer's instructions. First-strand cDNA was amplified using primers specific to ITPR 3 and hypoxanthine phosphoribosyltransferase (HPRT) genes. Copy numbers of ITPR 3 were calculated by referring standard curves and normalized by that of HPRT gene, of which expression levels are stable and not influenced by glucocorticoid (Russcher et al. 2005) as an internal control. Specific primer sequences are listed in Supplementary Table 5.

\section{Statistical analysis}

We assessed the association and Hardy-Weinberg equilibrium by the $\chi^{2}$ test and Fischer's extract test. Odds ratio was defined against the genotype consisting of non-risk homozygote and heterozygote of ITPR3, and non-risk homozygote of $N K X 2.5$. Luciferase assay data and realtime PCR data were analyzed by Student's $t$ test using Excel software (microsoft).

\section{Result}

Case-control association study

To identify a gene(s) that increases a risk for SLE, we applied a case-control association study by means of genome-wide gene-based SNP analysis as described previously (Kamatani et al. 2008). First, we analyzed 94 SLE (case 1) and 535 control subjects (control 1) at 52608 tag-SNP loci selected from JSNP database (Tsunoda et al. 2004) and successfully obtained genotype information at 50464 SNP loci. We compared the allelic frequencies of cases and controls by applying each of four genetic models (allelic frequency, genotype frequency, recessive and dominant models) and found 1,310 SNPs with $P$ values of 0.01 or smaller. These 1,310 SNPs were further analyzed for an additional panel consisting of 84 cases (case 2) and 361 controls (control 2). Statistical analysis of the combined samples identified an SNP located in $5^{\prime}$ franking of ITPR3 $(-1009 \mathrm{C}>\mathrm{T}, \quad$ rs3748079) to be significantly associated with $\operatorname{SLE}\left(P=2.87 \times 10^{-8}\right.$ in the recessive model with the odds ratio $=3.39,95 \% \mathrm{CI}$ of $2.16-5.32$ ) (Table 1). According to the LD analysis using genotyping data in Japanese population from the international HapMap project, the LD block that contains this SNP (rs3748079) was predicted to include $5^{\prime}$ part of ITPR 3 gene and none of adjutant genes (data not shown). Therefore, we considered ITPR 3 likely to be a disease-susceptible gene on this locus.

To construct a high-density LD map of this region, 50 tag-SNPs on ITPR3 or its adjacent genes with minor allele

Table 1 Association of the SNP in 5'flanking region of ITPR3 with SLE susceptibility

\begin{tabular}{|c|c|c|c|c|c|c|c|c|c|c|c|c|}
\hline \multirow[t]{3}{*}{ Samples } & \multicolumn{5}{|c|}{ Case } & \multicolumn{5}{|c|}{ Controls } & \multirow{3}{*}{$\begin{array}{l}\text { Odds ratio }(95 \% \mathrm{CI}) \\
\mathrm{CC} \text { vs } \mathrm{CT}+\mathrm{TT}\end{array}$} & \multirow{3}{*}{$\begin{array}{l}P \text { value } \\
\mathrm{CC} \text { vs } \mathrm{CT}+\mathrm{TT}\end{array}$} \\
\hline & \multirow[b]{2}{*}{$n$} & \multicolumn{3}{|c|}{ Genotype } & \multirow[b]{2}{*}{ Frequency $^{\mathrm{a}}$} & \multirow[b]{2}{*}{$n$} & \multicolumn{3}{|c|}{ Genotype } & \multirow[b]{2}{*}{ Frequency $^{\mathrm{a}}$} & & \\
\hline & & $\mathrm{CC}$ & CT & TT & & & $\mathrm{CC}$ & CT & TT & & & \\
\hline \multicolumn{13}{|l|}{ Screening } \\
\hline Case $1 /$ control 1 & 94 & 78 & 15 & 1 & 0.91 & 535 & 356 & 158 & 21 & 0.81 & $2.45(1.39-3 ;-4.32)$ & 0.0015 \\
\hline Case 2/control 2 & 83 & 75 & 7 & 1 & 0.95 & 361 & 229 & 118 & 14 & 0.80 & $5.4(2.53-3 ;-11.55)$ & $1.90 \mathrm{E}-06$ \\
\hline Total & 177 & 153 & 22 & 2 & 0.93 & 896 & 585 & 276 & 35 & 0.81 & $3.39(2.16-3 ;-5.32)$ & 2.87E-08 \\
\hline \multicolumn{13}{|l|}{ Replication } \\
\hline Case 3/control 3 & 365 & 275 & 84 & 6 & 0.87 & 981 & 673 & 288 & 20 & 0.83 & $1.4(1.06-3 ;-1.84)$ & 0.016 \\
\hline
\end{tabular}

$C I$ confidence interval, $n$ number of individuals

${ }^{\text {a }}$ Frequency of $\mathrm{C}$ allele 
frequency of 0.15 or higher were genotyped. Analysis of LD index $\left(D^{\prime}\right)$ between each SNP revealed that the marker SNP $(-1009 \mathrm{C}>\mathrm{T}$, rs3748079) locates on the LD block spanning from $16 \mathrm{~kb} 5^{\prime}$ flanking to intron 27 of ITPR3 gene (Fig. 1a). As the association to SLE was still peaked at this SNP, we considered ITPR 3 as a good candidate for a disease-susceptible gene. To further define a region of interest, we screened SNPs in the genomic region corresponding to ITPR3 locus and identified 5 SNPs in the promoter region, 9 SNPs in exons and 98 SNPs in introns. We additionally genotyped all non-synonymous SNPs and SNPs around transcription start of ITPR 3 gene (from $2 \mathrm{~kb}$ $5^{\prime}$ flanking to intron 3). Total of 75 SNPs on this locus were finally analyzed using 178 cases (case 1 and 2) and 361 controls (control 2) (Supplementary Table 1). However, none of the additional SNPs showed more significant association than the marker SNP $(-1009 \mathrm{C}>\mathrm{T}$, rs3748079) initially identified (Fig. 1a, b). The association peaked at this SNP and gradually weakened in both $5^{\prime}$ - and $3^{\prime}$ - direction. Then to validate the association of rs3748079 with SLE susceptibility, we performed replication study using an independent 365 cases (case 3) and 981 controls (control 3). As a result, the association of rs 3748079 was replicated in a recessive effect model $(P=0.016$ with the odds ratio $=1.40,95 \% \mathrm{CI}$ of $1.06-1.84$ ), indicating the possible roles of ITPR 3 gene in the pathogenesis of SLE.

\section{Association analysis of $H L A-D R B 1$ and $-B$ with SLE}

The SNP rs3748079 is located on chromosome 6p21, which was indicated to exhibit a significant association with SLE in previous reports (Croker and Kimberly 2005). MHC haplotypes are considered as candidates that
Fig. 1 Association of SNP $(-1009 \mathrm{C}>\mathrm{T}, \mathrm{rs} 3748079)$ in the ITPR3 gene with SLE. a $P$ value distribution at 75 SNP loci in a $200-\mathrm{Kb}$ region on chromosome 6p21-21.3. They were genotyped for 178 cases and 361 controls. This region contains six genes indicated above (LEMD2, IHPK3, C6orf125, ITPR3, FLJ43752 and $B A K 1)$. An SNP $(-1009 \mathrm{C}>\mathrm{T}, \mathrm{rs} 3748079)$ indicated by an arrowhead revealed one showing the strongest association with SLE. A lower part shows the pairwise LD between SNPs, as measured by $\mathrm{D}^{\prime}$ in 333 control subjects. We included SNPs with minor allele frequency of 0.15 or higher. $\mathbf{b}$ A detailed map of the SNP $(-1009 \mathrm{C}>\mathrm{T}$, rs3748079) in the $5^{\prime}$ franking region of ITPR3. Black boxes indicate the locations and relative sizes of 56 exons. The candidate functional SNP is located in the putative promoter region of the ITPR 3 gene

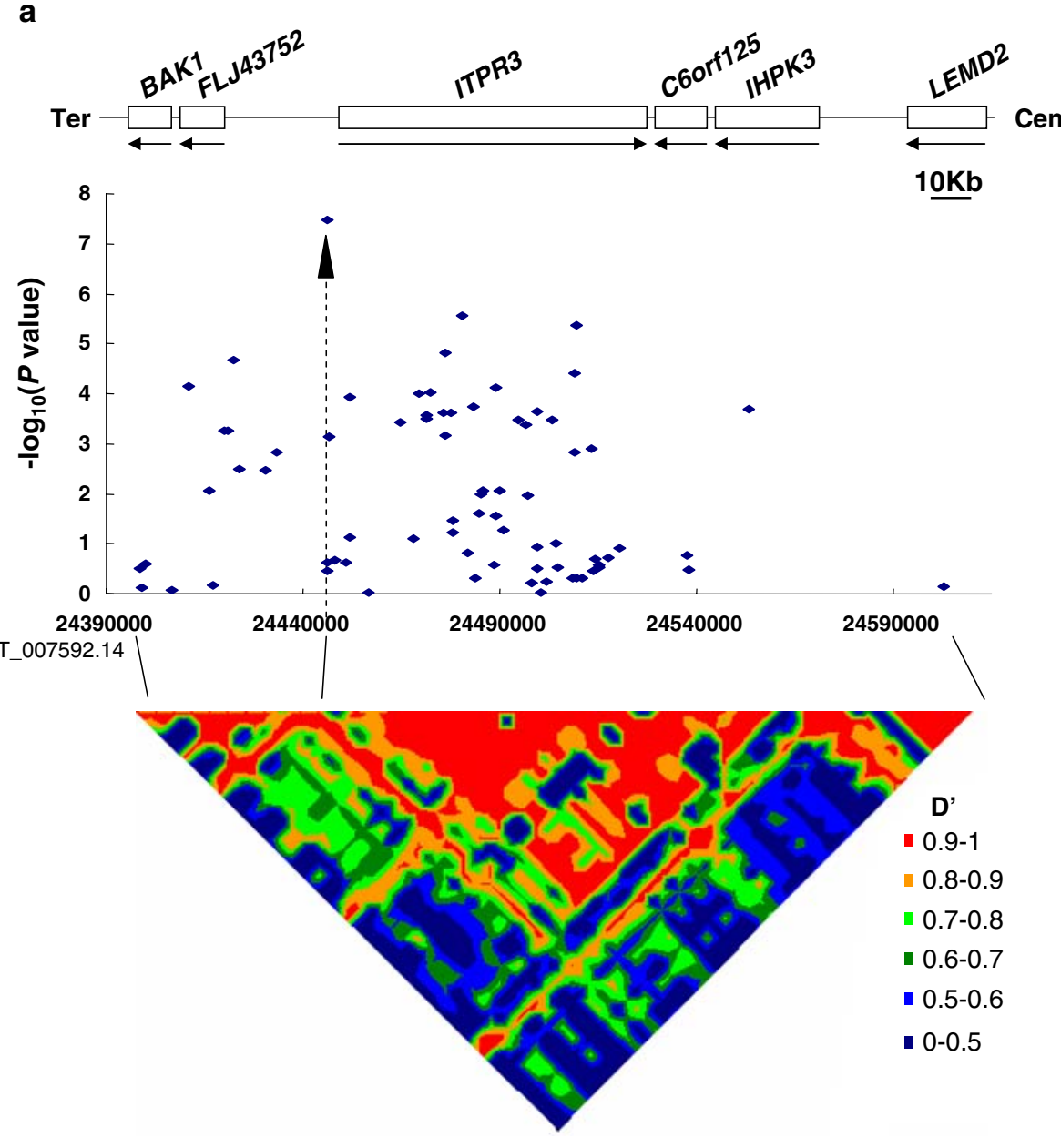

b

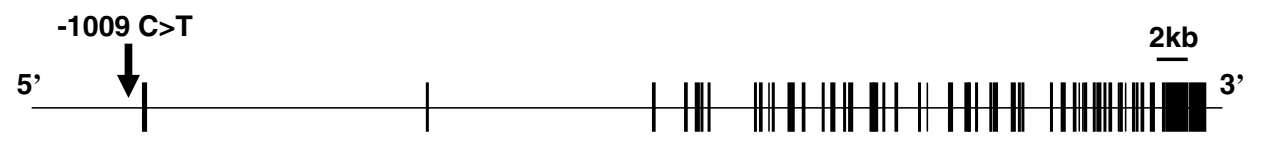


associate with SLE on this locus. However, in our genomewide case-control analysis, SNPs around the MHC region revealed weaker associations with SLE than this particular SNP (rs3748079) (Supplementary Fig. 1). In Japanese SLE, $H L A-D R B 1 * 1501$ and $H L A-B * 39$ were indicated to associate with SLE (Dong et al. 1993; Hashimoto et al. 1994; Hashimoto et al. 1985; Tsuchiya et al. 2002). Therefore, to exclude the possibility that the association of SNP (rs3748079) with SLE was due to an effect of linkage disequilibrium with these HLA loci, we genotyped HLA$D R B 1$ and HLA-B using 178 of case and 361 of control samples (cases 1, 2 and control 2). Our data indicated an association of $H L A-D R B 1 * 1501$ and $H L A-D R B 1 * 1502$ with SLE $(P=0.000024$ and $P=0.0000019$ with odds ratio of 2.43 and 0.29 respectively) (Supplementary Tables 2,3 ), but their associations were less significant than that of the SNP rs3748079 when we examined the same case and control samples $(P=0.0000000328$, with odd ratio of 3.67). Then we performed subgroup analysis based on HLA genotypes (Table 2). The association of SNP (rs3748079) with SLE remained consistent in three subgroups $(P=0.00000098-0.033$ with odds ratio of 2.993.56) among four subgroups analyzed.

Recently we identified the association of SNP rs3130342 on TNXB gene with SLE susceptibility (Kamatani et al. 2008). The TNXB gene is located on the same chromosomal region; however, the distance between ITPR 3 and TNXB genes is $1.5 \mathrm{Mb}$ and the pairwise $D^{\prime}$ value between them is very small $(0.03)$. Hence, the association of the SNP on the ITPR3 gene with SLE was considered to be independent from that on the TNXB gene or HLA genes.

SNP on ITPR3 gene associates with RA and Graves' disease

To further investigate the possible involvement of the ITPR 3 gene in other autoimmune diseases, we examined the association of this SNP (rs3748079) with RA and GD using 1,122 RA cases, 373 GD cases, and an additional 719 control samples (control 4). As summarized in Table 3, this SNP showed significant associations with SLE, RA, and GD $(P=0.0000000178$ with odds ratio of 1.88 , $P=0.0084$ with odds ratio of 1.23 , and $P=0.00036$ with odds ratio of 1.57 , respectively). The results of the association analyses indicated the $\mathrm{C}$ allele to be the susceptible allele and the $\mathrm{T}$ allele to be the non-susceptible allele in all three autoimmune diseases. These data suggested that ITPR3 is likely to be involved commonly in the susceptibility to multiple autoimmune diseases.

NKX2.5 binds at ITPR3 promoter and regulates ITPR3 expression

To investigate a possible functional role of this SNP, we performed electrophoresis mobility shift assay (EMSA)

Table 2 Subgroup analysis of SNP (rs 3748079) based on HLA-DRB1*1501and HLA-DRB1*1502

\begin{tabular}{|c|c|c|c|c|c|c|c|c|c|c|c|c|}
\hline & \multicolumn{5}{|c|}{ Case $1+$ case 2} & \multicolumn{5}{|c|}{ Control } & \multirow{3}{*}{$\begin{array}{l}\text { Odds ratio }(95 \% \mathrm{CI}) \\
\mathrm{CC} \text { vs } \mathrm{CT}+\mathrm{TT}\end{array}$} & \multirow{3}{*}{$\begin{array}{l}P \text { value } \\
\text { CC vs CT }+ \text { TT }\end{array}$} \\
\hline & \multirow[b]{2}{*}{$n$} & \multicolumn{3}{|c|}{ Genotype } & \multirow[b]{2}{*}{ Frequency $^{\mathrm{a}}$} & \multirow[b]{2}{*}{$n$} & \multicolumn{3}{|c|}{ Genotype } & \multirow[b]{2}{*}{ Frequency $^{\mathrm{a}}$} & & \\
\hline & & $\mathrm{CC}$ & CT & TT & & & $\mathrm{CC}$ & $\mathrm{CT}$ & $\mathrm{TT}$ & & & \\
\hline $\mathrm{DRB} 1 * 1501(+)$ & 52 & 45 & 7 & 0 & 0.93 & 50 & 34 & 16 & 0 & 0.84 & $2.99(1.03-9.61)$ & $3.3 \mathrm{E}-02$ \\
\hline DRB1*1501 (-) & 123 & 104 & 17 & 2 & 0.91 & 314 & 197 & 103 & 14 & 0.79 & $3.24(1.86-5.9)$ & $6.1 \mathrm{E}-06$ \\
\hline $\mathrm{DRB} 1 * 1502(+)$ & 14 & 7 & 5 & 2 & 0.68 & 92 & 47 & 41 & 4 & 0.73 & $0.96(0.26-3.48)$ & $1.0 \mathrm{E}+00$ \\
\hline DRB1*1502 (-) & 161 & 142 & 19 & 0 & 0.94 & 272 & 184 & 78 & 0 & 0.82 & $3.56(2.04-6.5)$ & $9.8 \mathrm{E}-07$ \\
\hline
\end{tabular}

CI confidence interval, $n$ number of individuals

${ }^{\text {a }}$ Frequency of $\mathrm{C}$ allele

Table 3 Association of SNP (rs 3748079) with SLE, RA and BD

\begin{tabular}{|c|c|c|c|c|c|c|c|}
\hline \multirow[t]{2}{*}{ Disease } & \multirow[b]{2}{*}{$n$} & \multicolumn{3}{|c|}{ Genotype } & \multirow[t]{2}{*}{ Allele $\mathrm{C}$ frequency } & \multirow{2}{*}{$\begin{array}{l}\text { Odds ratio }(95 \% \mathrm{CI}) \\
\mathrm{CC} \text { vs } \mathrm{CT}+\mathrm{TT}\end{array}$} & \multirow{2}{*}{$\begin{array}{l}P \text { value } \\
\mathrm{CC} \text { vs } \mathrm{CT}+\mathrm{TT}\end{array}$} \\
\hline & & $\mathrm{CC}$ & $\mathrm{CT}$ & TT & & & \\
\hline SLE & 542 & 428 & 106 & 8 & 0.89 & $1.88(1.51-2.35)$ & $1.78 \mathrm{E}-08$ \\
\hline RA & 1,122 & 797 & 290 & 35 & 0.84 & $1.23(1.05-1.43)$ & 0.0084 \\
\hline GD & 373 & 283 & 84 & 6 & 0.87 & $1.57(1.22-2.02)$ & 0.00036 \\
\hline Control & 2,596 & 1,730 & 784 & 82 & 0.82 & & \\
\hline
\end{tabular}

$R A$ rhematoid arthritis, GD Graves's disease, $S L E$ systemic lupus erythematosus, $C I$ confidence interval, $n$ number of individuals 
using two 17-bp oligonucleotides, one corresponding to the susceptible C-allele and the other to the non- susceptible T-allele of the SNP (Fig. 2a). After incubation of the labeled oligonucleotide with nuclear extracts from Jurkat or HEK293T cells (Fig. 2b, c), we performed electrophoresis and found the binding of a nuclear protein(s) specifically to the T-allele oligonucleotide. Screening of TRANSFAC database (Heinemeyer et al. 1998) indicated a transcriptional factor, NKX2.5, to be a candidate molecule to bind to this DNA segment corresponding to the Tallele, but not to that of the C-allele (Fig. 2a). Competition assays with the unlabeled NKX2.5-binding consensus oligonucleotide (Chen and Schwartz 1995) completely inhibited the DNA-protein complex formation (Fig. 2b). Furthermore, when we used nuclear extracts prepared from HEK293T cells that were transfected with pCAGGSHA-NKX2.5 plasmid (designed to express NKX2.5 with an HA tag), the intensity of the shifted band was remarkably enhanced. By addition of anti-HA antibody to the mixture of the oligonucleotide and nuclear extracts, the band was further shifted at the higher molecular position, indicating the specific binding of the NKX2.5 protein to the T-allele oligonucleotide (Fig. 2c). We also carried out a chromatin immunoprecipitation (CHIP) assay using HEK293T cells that were found to be a homozygote of the $\mathrm{T}$ allele. We transfected HEK293T cells with pCAGGSHA-NKX2.5 plasmid or mock plasmid, and then DNAprotein complex was precipitated using anti-HA antibody. Subsequent PCR experiments indicated that NKX2.5 bound to a genomic fragment corresponding to the $\mathrm{T}$ allele in vivo (Fig. 2d).

Then we carried out the reporter assay using luciferase constructs that contained eight copies of the 17-bp oliginucleotide at the upstream region of pGL3-promotor vector. Exogenously introduced NKX2.5 enhanced the luciferase activity in the cells transfected with the plasmid containing the $\mathrm{T}$ allele in a dose-dependent manner, but no enhancement was observed with the plasmid containing the $\mathrm{C}$ allele (Fig. 2e). Taken together, the subjects with the disease-susceptible $\mathrm{C}$ allele are expected to have lower expression of ITPR 3 and that might result in the resistance to the apoptotic signaling pathway in $\mathrm{T}$ cells.

SNP on NKX2.5 gene also associates with SLE and RA susceptibility

To subsequently examine the involvement of the $N K X 2.5$ gene (located on chromosome 5q34) in susceptibility to SLE and RA, we genotyped three SNPs in the NKX2.5 gene that were deposited in the JSNP database (Tsunoda et al. 2004), using 178 SLE cases, 1,115 RA case, and 1,425 controls. Interestingly, we found that an SNP
$(-1192 \mathrm{C}>\mathrm{T}, \mathrm{rs} 3095870)$ located in $5^{\prime}$ franking region of the $N K X 2.5$ gene was also significantly associated with SLE $(P=0.0037$, odds ratio $=1.74,95 \%$ CI of $1.19-2.55)$ and RA $(P=0.042$, odds ratio $=1.24$, respectively, $95 \%$ CI of 1.01-1.54) (Supplementary Table 4). In addition, the individuals having risk genotypes for both ITPR3 and NKX2.5 genes showed a higher risk for SLE (odds ratio $=5.77,95 \%$ CI of $3.17-10.19$ ) and RA (odds ratio $=1.75,95 \% \mathrm{CI}$ of $1.32-2.32$ ) (Fig. 3a, b, Supplementary Table 5). NKX2.5 risk genotype (CT $+\mathrm{TT})$ conferred higher risk for SLE (odds ratio of 2.11 with $95 \%$ CI of 1.58-2.82) in the individuals with the risk genotype of ITPR3 (CC). On the other hand, NKX2.5 risk genotype didn't confer higher risk (odds ratio of 0.69 with $95 \%$ C.I. of 0.20-2.35) in the individuals with the non-risk genotype of ITPR3 $(\mathrm{CT}+\mathrm{TT})$. These results suggested the presence of genetic interaction between these two loci. However, 95\% CI showed some overlap; synergistic effect of these two loci in SLE susceptibility did not reach statistical significance.

SNP $(-1009 \mathrm{C}>\mathrm{T}, \mathrm{rs} 3748079)$ regulates ITPR3 expression in vivo

We then quantified the differences of ITPR3 mRNA expression using various cell lines with different genetic backgrounds for this particular SNP. Introduction of NKX2.5 enhanced the ITPR 3 expression in the cells having T allele such as HEK293T (T/T) and HepG2 and A549 cells (T/C), but did not enhance it in those without the $\mathrm{T}$ allele such as H1299, Hela and SBC5 cells (Fig. 3c). These findings further implied that NKX2.5 could enhance the expression of ITPR 3 through binding to the $\mathrm{T}$ allele that is likely to be a protective allele for SLE. Under stress conditions, glucocorticoid is released and induces a variety of physiological effects including immune suppression (Eskandari and Sternberg 2002; Eskandari et al. 2003). ITPR3 up-regulation is known to be indispensable in the glucocorticoid-induced apoptotic pathway in T lymphocytes. To examine possible effects of the functional candidate SNP on the glucocorticoidsignaling pathway, we measured the ITPR 3 expression in peripheral mononuclear blood cells from healthy volunteers. In response to treatment with $10 \mathrm{nM}$ dexamethasone, ITPR3 mRNA expression was significantly up-regulated in the cells with the heterozygote genotype containing a non-susceptible $\mathrm{T}$ allele, compared with those with the susceptible $\mathrm{C} / \mathrm{C}$ allele (Fig. 3d). Our data suggested that the disease-susceptible SNP might affect the response to glucocorticoid, and the individuals with non-susceptible $\mathrm{T}$ allele would have higher ITPR3 expression under the stress condition. 

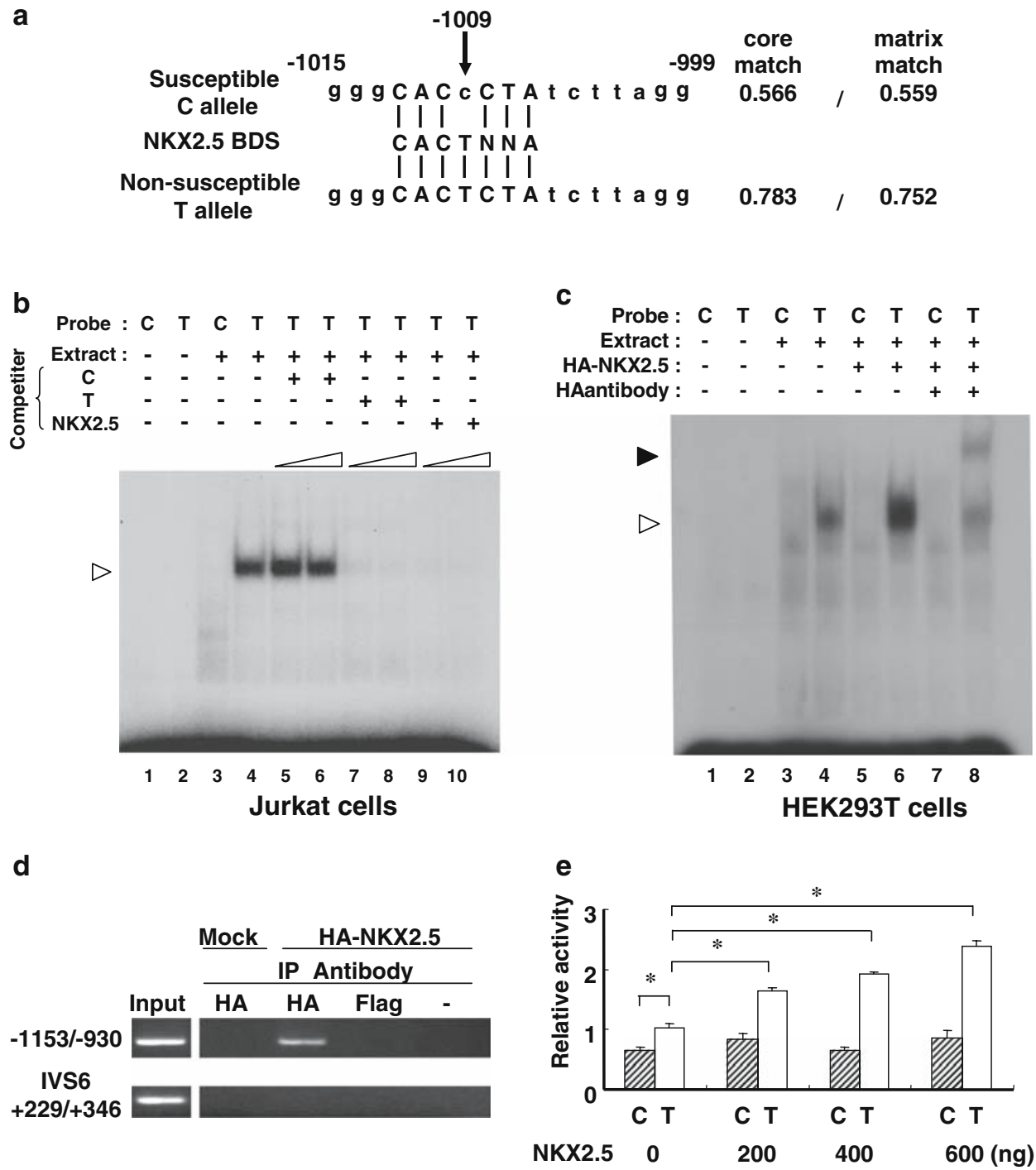

Fig. 2 Binding affinity of a nuclear factor(s) to the 17-bp oligonucleotide sequence corresponding to the candidate SNP $(-1009 \mathrm{C}>\mathrm{T}$, rs3748079). a DNA sequences of 17-base oligonucleotide used for EMSA. 5'-CACTNNA- $3^{\prime}$ is the consensus binding-sequence for NKX2.5. From the search using the TRANSFAC database, NKX2.5 was predicted to bind to the non-susceptible $\mathrm{T}$ allele, but not to the susceptible $\mathrm{C}$ allele. Nucleotides in capital letters represent correspondence to the NKX2.5 consensus-binding sequence. b Allelic differences and competition experiments using Jurkat cells. Stronger binding of a nuclear protein(s) to the oligonucleotide (open arrow) is observed in the lane containing the $\mathrm{T}$ allele probe (lane 4), but not to that of the C-allele (lane 3). Fifty- and 100-fold excesses of nonlabeled oligonucleotides were added to the mixture (lanes 5-8). Nonlabeled oligonucleotides corresponding to the $\mathrm{T}$ allele (lanes 7,8 ) as well as the NKX2.5 consensus oligonucleotides (lanes 9,10) inhibited formation of the DNA-protein complex, but non-labeled $\mathrm{C}$ allele oligonucleotide (lanes 5,6) did not. c Allelic differences and supershift experiments using HEK $293 \mathrm{~T}$ cells. Strong binding of nuclear proteins to oligonucleotide (open arrow) is observed in the lane containing the $\mathrm{T}$ allele oligonucleotide (lane 4). Intensity of a shifted band was increased by addition of nuclear proteins from cells that

were ectopically introduced to the NKX2.5 expression vector (pCAGGS-HA-NKX2.5) (lane 6). Closed arrow indicates the DNAprotein complex that was super-shifted by a further addition of HA antibodies (lane 8). d ChIP assays of the NKX2.5-binding sequence using HEK293T cells (homozygous with non-susceptible T-allele). After the cells were transfected with expression vectors, DNA-protein complex was immunoprecipitated (IP) with antibodies to HA or Flag, or only with agarose. Sets of primers designated to amplify the genomic sequence of ITPR3 ( $-1,153 / 930 ; 5^{\prime}$ flanking, IVS6 + 229/ 346; intron 6) were used for PCR. Each lane showed PCR product amplified by the use of the genomic DNA isolated from the cells transfected with mock (lane 2) or pCAGGS/NKX2.5-HA (lane 1,3-5) as a template. e Reporter assay using luciferase constructs that contained eight tandem copies of DNA sequence corresponding to the SNP region in pGL3-promoter vector using Jurkat cells. NKX2.5 enhanced the luciferase activity of the construct containing of the non-susceptible $\mathrm{T}$ allele sequence in a dose-dependent manner, but did not enhance that containing the susceptible $\mathrm{C}$ allele sequence. Data show the mean $\pm \mathrm{SD}$ of the relative activity from three experiments. Asterisk indicates $P<0.01$ by Student's $t$ test 
a

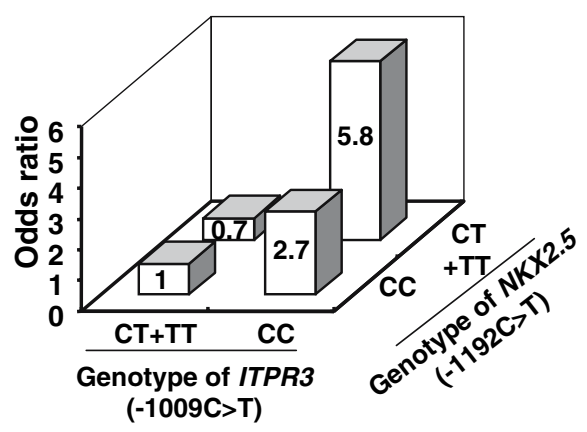

C

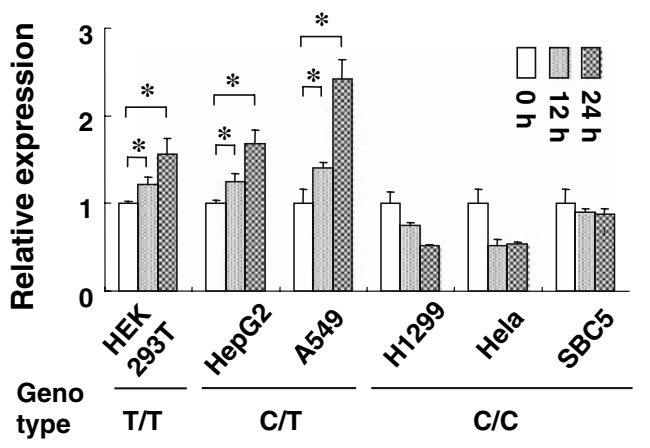

Fig. 3 Allele-specific transactivation of ITPR3 expression by $N K X 2.5$ and combinatorial effect of these two genes. a, b Combinatorial effect of an SNP $(-1009 \mathrm{C}>\mathrm{T})$ of ITPR3 and an SNP $(-1192 \mathrm{C}>\mathrm{T})$ of $N K X 2.5$. Risk genotypes are defined as the homozygote of the susceptible allele for ITPR3 (CC), and homozygote or heterozygote for the susceptible allele for $N K X 2.5$ $(\mathrm{CT}+\mathrm{TT})$. The individuals with the susceptible genotypes of both ITPR 3 and NKX2.5 showed higher odds-ratio than those with one or no susceptible genotype. Case 1 and 2 samples for SLE $(n=174)$, all RA subjects $(n=1113)$, and control 2,4 , and a part of control 3 samples $(n=1,417)$ were employed in this analysis. Detailed information is indicated in Supplementary Table 5. c Relative expression of ITPR3 in several cell lines (HEK293T, HepG2, A549,

\section{Discussion}

To identify a gene(s) that increases a risk for SLE, we applied a case-control association study using 52,608 genebased SNPs and identified the significant association of the SNP in the ITPR3 promoter region with SLE. ITPR3 is located on chromosome $6 \mathrm{p} 21$, one of the candidate loci that were indicated to associate with SLE by linkage analysis (Croker and Kimberly 2005). MHC haplotypes and/or C4A deficiency are considered as candidates on this locus. In fact, several studies have shown an increased frequency of $H L A-D R B 1 * 1501$ and $H L A-D R B 1 * 0301$ alleles in Caucasian SLE patients (Harley et al. 1998), while HLA$D R B 1 * 1501$ allele has commonly been associated with disease susceptibility in most Asian populations (Fong and Boey 1998). Complete deficiency of C4A is also associated with a very high incidence of SLE in Caucasians (Yang b

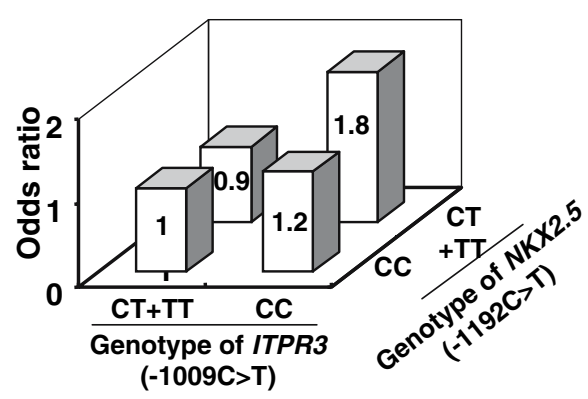

d

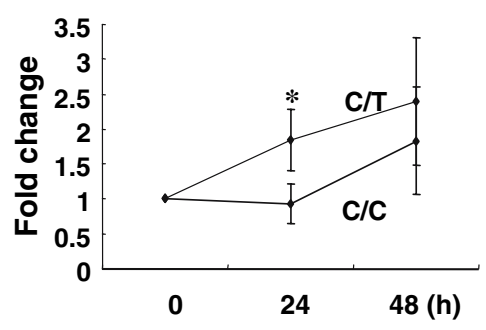

H1299, Hela, and SBC5) that were transfected with the NKX2.5 expression vector. ITPR 3 mRNA expressions were up-regulated in the cells containing the non-susceptible T allele (HEK293T, HepG2, A549), but not in those containing only susceptible C allele (H1299, Hela, and SBC5). Expression of $B 2 M$ was served as an internal control. Asterisk indicates $P<0.01$ by Student's $t$ test. d Different levels of ITPR3 mRNA induction in individuals with different genotypes. PBMCs from healthy volunteers homozygous $(n=7)$ or heterozygous $(n=6)$ for the $C$ allele were stimulated with $10 \mathrm{nM}$ of dexamethasone for 24 or $48 \mathrm{~h}$. Relative expression of ITPR 3 mRNA was calculated in comparison with unstimulated samples. Expression of HPRT was served as an internal control. Data show the mean \pm SD. Asterisk indicates $P<0.01$ by Student's $t$ test

et al. 2004), but was rare in Japanese SLE patients (Yamada et al. 1990). These observations suggest genetic backgrounds that determine the susceptibility to SLE might be different among different ethnic groups.

The ITPR 3 gene was located on the $6 \mathrm{p} 21$ locus, but was not included within the $7.5-\mathrm{Mb}$ extended $\mathrm{MHC}$ region (about $200 \mathrm{~KB}$ centromeric to the extended class II subregion) (Horton et al. 2004). Our case control genome-wide analysis indicated that SNP in the ITPR3 gene revealed more significant association with SLE than the SNPs around MHC region. Moreover, linkage disequilibrium analysis indicated that ITPR3 SNP and HLA genes are located in different LD blocks. We also genotyped $H L A$ $D R B 1$ and HLA-B genes that were indicated to be associated with SLE in Japanese SLE cases and found a significant association of $H L A-D R B 1 * 1501$ and $H L A$ $D R B 1 * 1502$ with SLE. However, the subgroup analysis 
revealed that rs3748079 associated with SLE independent from these HLA alleles. Furthermore, the association of the SNP was replicated in independent SLE case-control samples, and the association was also observed in other types of autoimmune diseases, RA and GD. Interestingly, we identified that the transcription factor NKX2.5 bound the promoter DNA segment including this SNP and activated the transcription of ITPR 3 gene in the allele-specific manner. Our data clearly imply that ITPR3 is one of the disease-susceptible genes on 6p11-21 (Tsao 2004) and also suggest that this genetic factor is associated commonly with multiple autoimmune diseases.

Three subtypes of inositol 1,4,5-triphosphate receptor have been identified in mammals (Furuichi et al. 1994). They are located on ER and mediate $\mathrm{Ca}^{2+}$ mobilization from ER to cytoplasm in response to inositol 1,4,5-trisphosphate (Patterson et al. 2004). ITPR1 is predominantly expressed in brain tissue and plays a critical role in the regulation of motor and learning systems, and two other subtypes, ITPR2 and ITPR3, are expressed in various tissues and cell lines (Higo et al. 2005; Nishiyama et al. 2000; Taylor et al. 1999). Recent studies have demonstrated that ITPR3 plays a crucial role in regulation of apoptotic factors (Blackshaw et al. 2000; Hanson et al. 2004; Mendes et al. 2005). Cytoplasmic $\mathrm{Ca}^{2+}$ activates calcineurin followed by the activation of BAD and NFATc (nuclear factors of activated $\mathrm{T}$ cells). Activated $\mathrm{BAD}$, a member of the proapoptotic BCL-2 family, augments apoptosis of $\mathrm{T}$ cells by forming heterodimers with BCL-2 and suppressing their proliferative activity (Jayaraman and Marks 2000). Concordantly, activation of NFATc results in $\mathrm{T}$ cell proliferation through the transcriptional control of lymphokines (Jayaraman and Marks 2000). Higher ITPR3 activity was shown to induce apoptosis of $\mathrm{T}$ lymphocyte (Blackshaw et al. 2000; Hanson et al. 2004; Mendes et al. 2005), which may eliminate autoreactive $\mathrm{T}$ cells and decrease the risk to have autoimmune reactions (Green et al. 2003; Rathmell and Thompson 2002; Refaeli et al. 1998). Disease-susceptible SNP found in the ITPR3 gene may be associated with dysfunction of the apoptotic pathway in T lymphocytes, which is a common observation in SLE patients (Rosen and Casciola-Rosen 1999; Salmon and Gordon 1999).

Recently, ITPR3 was shown to be associated with type 1 diabetes (T1D) in the Swedish population (Roach et al. 2006). T1D is an autoimmune disease with cellular and humoral immunological abnormalities (Atkinson and Eisenbarth 2001) and characterized with destruction of pancreatic islet beta cells. The SNP (rs2296336, IVS17 $+249 \mathrm{C} / \mathrm{G})$ that was reported to be associated with T1D revealed a less significant association $(P=0.00032)$ with SLE in our tested samples (Supplementary Table 1). The functional SNP that we identified in the ITPR3 promoter was not examined in the Swedish T1D population. The association of these SNPs with T1D in the Japanese population should be examined in the future; however, this association strengthens our conclusion that the genetic variations in the ITPR 3 gene are likely to be genetic factors common in various autoimmune diseases.

NKX2.5 is known to be a homeobox protein with transcriptional activity that is essential in a developmental stage of heart and is also known to regulate immune response through the transcriptional control of lymphokines (Dupays et al. 2005; Schwartz and Olson 1999). One SNP on NKX2.5 also revealed a significant association with SLE and RA, and the individuals who have risk genotypes for both ITPR3 and NKX2.5 genes have increased risk for SLE and RA. Interestingly, in two cell lines with the homozygous $\mathrm{C}$ allele of ITPR3 SNP, ectopic expression of NKX2.5 suppressed ITPR3 mRNA (Fig. 3c), suggesting the possible suppressive effect of NKX2.5 on ITPR3 expression through the other promoter region distinct from SNP rs3748079 locus. In that case, the effect of NKX2.5 on SLE susceptibility would be affected by ITPR3 genotype. The result of Fig. 3a is concordant with this hypothesis. Although the relationship between $N K X 2.5$ and autoimmune reactions should be further clarified in the future, our data demonstrate that genetic and functional interactions of ITPR 3 and NKX2.5 play a crucial role in the pathogenesis of SLE.

In summary, through the case-control association study using a large number of gene-based SNPs screening, we have demonstrated that SNPs in the ITPR3 and NKX2.5 gene are likely to be candidate SNPs related to an increased risk for SLE. Our results imply that SNPs of ITPR3 and $N K X 2.5$ are novel genetic determinants for susceptibility to SLE possibly by the regulation in the apoptotic pathway of auto-reactive $\mathrm{T}$ cells.

Acknowledgments We wish to thank Dr. Michiaki Kubo and Dr. Chizu Tanikawa for advice and useful discussion. We are grateful to the members of the Rotary Club of Osaka-Midosuji District 2660 Rotary International in Japan for supporting our study.

\section{References}

Arnett FC, Edworthy SM, Bloch DA, McShane DJ, Fries JF, Cooper NS, Healey LA, Kaplan SR, Liang MH, Luthra HS (1988) The American Rheumatism Association 1987 revised criteria for the classification of rheumatoid arthritis. Arthritis Rheum 31:315324

Atkinson MA, Eisenbarth GS (2001) Type 1 diabetes: new perspectives on disease pathogenesis and treatment. Lancet 358:221-229

Blackshaw S, Sawa A, Sharp AH, Ross CA, Snyder SH, Khan AA (2000) Type 3 inositol 1,4,5-trisphosphate receptor modulates cell death. Faseb J 14:1375-1379

Chen CY, Schwartz RJ (1995) Identification of novel DNA binding targets and regulatory domains of a murine tinman homeodomain factor, nkx-25. J Biol Chem 270:15628-15633 
Croker JA, Kimberly RP (2005) Genetics of susceptibility and severity in systemic lupus erythematosus. Curr Opin Rheumatol 17:529-537

Deapen D, Escalante A, Weinrib L, Horwitz D, Bachman B, RoyBurman P, Walker A, Mack TM (1992) A revised estimate of twin concordance in systemic lupus Erythematosus. Arthritis Rheum 35:311-318

Dong RP, Kimura A, Hashimoto H, Akizuki M, Nishimura Y, Sasazuki T (1993) Difference in HLA-linked genetic background between mixed connective tissue disease and systemic lupus erythematosus. Tissue Antigens 41:20-25

Dupays L, Jarry-Guichard T, Mazurais D, Calmels T, Izumo S, Gros D, Theveniau-Ruissy M (2005) Dysregulation of connexins and inactivation of NFATc1 in the cardiovascular system of Nkx2-5 null mutants. J Mol Cell Cardiol 38:787-798

Eskandari F, Sternberg EM (2002) Neural-immune interactions in health and disease. Ann N Y Acad Sci 966:20-27

Eskandari F, Webster JI, Sternberg EM (2003) Neural immune pathways and their connection to inflammatory diseases. Arthritis Res Ther 5:251-265

Fong KY, Boey ML (1998) The genetics of systemic lupus Erythematosus. Ann Acad Med Singapore 27:42-46

Furuichi T, Kohda K, Miyawaki A, Mikoshiba K (1994) Intracellular channels. Curr Opin Neurobiol 4:294-303

Gaffney PM, Ortmann WA, Selby SA, Shark KB, Ockenden TC, Rohlf KE, Walgrave NL, Boyum WP, Malmgren ML, Miller ME, Kearns GM, Messner RP, King RA, Rich SS, Behrens TW (2000) Genome screening in human systemic lupus erythematosus: results from a second Minnesota cohort and combined analyses of 187 sib-pair families. Am J Hum Genet 66:547-556

Green DR, Droin N, Pinkoski M (2003) Activation-induced cell death in T cells. Immunol Rev 193:70-81

Han M, Tan YQ, Zhang Y, Tsai J, Vorhaben R, Moraes JR, Moraes ME, Stastny P (2003) Multiplex single nucleotide extension: a robust and high throughput method for HLA-A locus typing. Hum Immunol 64:1111-1122

Hanson CJ, Bootman MD, Roderick HL (2004) Cell signalling: IP3 receptors channel calcium into cell death. Curr Biol 14:R933-935

Harley JB, Moser KL, Gaffney PM, Behrens TW (1998) The genetics of human systemic lupus Erythematosus. Curr Opin Immunol 10:690-696

Hashimoto H, Nishimura Y, Dong RP, Kimura A, Sasazuki T, Yamanaka K, Tokano Y, Murashima A, Kabasawa K, Hirose S (1994) HLA antigens in Japanese patients with systemic lupus erythematosus. Scand J Rheumatol 23:191-196

Hashimoto H, Tsuda H, Matsumoto T, Nasu H, Takasaki Y, Shokawa Y, Hirose S, Terasaki PI, Iwaki Y (1985) HLA antigens associated with systemic lupus erythematosus in Japan. J Rheumatol 12:919-923

Hata J, Matsuda K, Ninomiya T, Yonemoto K, Matsushita T, Ohnishi Y, Saito S, Kitazono T, Ibayashi S, Iid M, Kiyohara Y, Nakamura Y, Kubo M (2007) Functional SNP in an Sp1-binding site of AGTRL1 gene is associated with susceptibility to brain infarction. Hum Mol Genet 16:630-639

Heinemeyer T, Wingender E, Reuter I, Hermjakob H, Kel AE, Kel OV, Ignatieva EV, Ananko EA, Podkolodnaya OA, Kolpakov FA, Podkolodny NL, Kolchanov NA (1998) Databases on transcriptional regulation: TRANSFAC, TRRD and COMPEL. Nucleic Acids Res 26:362-367

Higo $T$, Hattori M, Nakamura T, Natsume $T$, Michikawa $T$, Mikoshiba K (2005) Subtype-specific and ER lumenal environment-dependent regulation of inositol 1,4,5-trisphosphate receptor type 1 by ERp44. Cell 120:85-98

Hochberg MC (1997) Updating the American College of Rheumatology revised criteria for the classification of systemic lupus Erythematosus. Arthritis Rheum 40:1725
Horton R, Wilming L, Rand V, Lovering RC, Bruford EA, Khodiyar VK, Lush MJ, Povey S, Talbot CC, Wright MW, Wain HM, Trowsdale J, Ziegler A, Beck S (2004) Gene map of the extended human MHC. Nat Rev Genet 5:889-899

Jayaraman T, Marks AR (2000) Calcineurin is downstream of the inositol 1,4,5-trisphosphate receptor in the apoptotic and cell growth pathways. J Biol Chem 275:6417-6420

Kamatani Y, Matsuda K, Ohishi T, Ohtsubo S, Yamazaki K, Iida A, Hosono N, Kubo M, Yumura W, Nitta K, Katagiri T, Kawaguchi Y, Kamatani N, Nakamura Y (2008) Identification of a significant association of an SNP in TNXB with SLE in Japanese population. J Hum Genet 53:64-73

Khan AA, Soloski MJ, Sharp AH, Schilling G, Sabatini DM, Li SH, Ross CA, Snyder SH (1996) Lymphocyte apoptosis: mediation by increased type 3 inositol 1,4,5-trisphosphate receptor. Science 273:503-507

Kizawa H, Kou I, Iida A, Sudo A, Miyamoto Y, Fukuda A, Mabuchi A, Kotani A, Kawakami A, Yamamoto S, Uchida A, Nakamura K, Notoya K, Nakamura Y, Ikegawa S (2005) An aspartic acid repeat polymorphism in asporin inhibits chondrogenesis and increases susceptibility to osteoarthritis. Nat Genet 37:138-144

Kochi Y, Yamada R, Suzuki A, Harley JB, Shirasawa S, Sawada T, Bae SC, Tokuhiro S, Chang X, Sekine A, Takahashi A, Tsunoda T, Ohnishi Y, Kaufman KM, Kang CP, Kang C, Otsubo S, Yumura W, Mimori A, Koike T, Nakamura Y, Sasazuki T, Yamamoto K (2005) A functional variant in FCRL3, encoding Fc receptor-like 3, is associated with rheumatoid arthritis and several autoimmunities. Nat Genet 37:478-485

Kubo M, Hata J, Ninomiya T, Matsuda K, Yonemoto K, Nakano T, Matsushita T, Yamazaki K, Ohnishi Y, Saito S, Kitazono T, Ibayashi S, Sueishi K, Iida M, Nakamura Y, Kiyohara Y (2007) A nonsynonymous SNP in PRKCH (protein kinase C eta) increases the risk of cerebral infarction. Nat Genet 39:212-217

Mendes CC, Gomes DA, Thompson M, Souto NC, Goes TS, Goes AM, Rodrigues MA, Gomez MV, Nathanson MH, Leite MF (2005) The type III inositol 1,4,5-trisphosphate receptor preferentially transmits apoptotic $\mathrm{Ca}^{2+}$ signals into mitochondria. J Biol Chem 280:40892-40900

Merrell M, Shulman LE (1955) Determination of prognosis in chronic disease, illustrated by systemic lupus Erythematosus. J Chronic Dis $1: 12-32$

Nishiyama M, Hong K, Mikoshiba K, Poo MM, Kato K (2000) Calcium stores regulate the polarity and input specificity of synaptic modification. Nature 408:584-588

Ohnishi Y, Tanaka T, Ozaki K, Yamada R, Suzuki H, Nakamura Y (2001) A high-throughput SNP typing system for genome-wide association studies. J Hum Genet 46:471-477

Ozaki K, Sato H, Iida A, Mizuno H, Nakamura T, Miyamoto Y, Takahashi A, Tsunoda T, Ikegawa S, Kamatani N, Hori M, Nakamura Y, Tanaka T (2006) A functional SNP in PSMA6 confers risk of myocardial infarction in the Japanese population. Nat Genet 38:921-925

Patterson RL, Boehning D, Snyder SH (2004) Inositol 1,4,5trisphosphate receptors as signal integrators. Annu Rev Biochem 73:437-465

Rathmell JC, Thompson CB (2002) Pathways of apoptosis in lymphocyte development, homeostasis, and disease. Cell 109(Suppl):S97-107

Refaeli Y, Van Parijs L, London CA, Tschopp J, Abbas AK (1998) Biochemical mechanisms of IL-2-regulated Fas-mediated T cell apoptosis. Immunity 8:615-623

Roach JC, Deutsch K, Li S, Siegel AF, Bekris LM, Einhaus DC, Sheridan CM, Glusman G, Hood L, Lernmark A, Janer M (2006) Genetic mapping at 3-kilobase resolution reveals inositol 1,4,5triphosphate receptor 3 as a risk factor for type 1 diabetes in Sweden. Am J Hum Genet 79:614-627 
Rosen A, Casciola-Rosen L (1999) Autoantigens as substrates for apoptotic proteases: implications for the pathogenesis of systemic autoimmune disease. Cell Death Differ 6:6-12

Russcher H, Smit P, van den Akker EL, van Rossum EF, Brinkmann AO, de Jong FH, Lamberts SW, Koper JW (2005) Two polymorphisms in the glucocorticoid receptor gene directly affect glucocorticoid-regulated gene expression. J Clin Endocrinol Metab 90:5804-5810

Salmon M, Gordon C (1999) The role of apoptosis in systemic lupus Erythematosus. Rheumatology (Oxford) 38:1177-1183

Schwartz RJ, Olson EN (1999) Building the heart piece by piece: modularity of cis-elements regulating $\mathrm{Nkx} 2-5$ transcription. Development 126:4187-4192

Seki S, Kawaguchi Y, Chiba K, Mikami Y, Kizawa H, Oya T, Mio F, Mori M, Miyamoto Y, Masuda I, Tsunoda T, Kamata M, Kubo T, Toyama Y, Kimura T, Nakamura Y, Ikegawa S (2005) A functional SNP in CILP, encoding cartilage intermediate layer protein, is associated with susceptibility to lumbar disc disease. Nat Genet 37:607-612

Shanks N, Moore PM, Perks P, Lightman SL (1999) Alterations in hypothalamic-pituitary-adrenal function correlated with the onset of murine SLE in MRL +/+ and lpr/lpr mice. Brain Behav Immun 13:348-360

Sternberg EM, Chrousos GP, Wilder RL, Gold PW (1992) The stress response and the regulation of inflammatory disease. Ann Intern Med 117:854-866

Suzuki A, Yamada R, Chang X, Tokuhiro S, Sawada T, Suzuki M, Nagasaki M, Nakayama-Hamada M, Kawaida R, Ono M, Ohtsuki M, Furukawa H, Yoshino S, Yukioka M, Tohma S, Matsubara T, Wakitani S, Teshima R, Nishioka Y, Sekine A, Iida A, Takahashi A, Tsunoda T, Nakamura Y, Yamamoto K (2003) Functional haplotypes of PADI4, encoding citrullinating enzyme peptidylarginine deiminase 4, are associated with rheumatoid arthritis. Nat Genet 34: 395-402

Taylor CW, Genazzani AA, Morris SA (1999) Expression of inositol trisphosphate receptors. Cell Calcium 26:237-251

Tokuhiro S, Yamada R, Chang X, Suzuki A, Kochi Y, Sawada T, Suzuki M, Nagasaki M, Ohtsuki M, Ono M, Furukawa H,
Nagashima M, Yoshino S, Mabuchi A, Sekine A, Saito S, Takahashi A, Tsunoda T, Nakamura Y, Yamamoto K (2003) An intronic SNP in a RUNX1 binding site of SLC22A4, encoding an organic cation transporter, is associated with rheumatoid arthritis. Nat Genet 35:341-348

Tsao BP (2003) The genetics of human systemic lupus erythematosus. Trends Immunol 24:595-602

Tsao BP (2004) Update on human systemic lupus erythematosus genetics. Curr Opin Rheumatol 16:513-521

Tsuchiya N, Ohashi J, Tokunaga K (2002) Variations in immune response genes and their associations with multifactorial immune disorders. Immunol Rev 190:169-181

Tsunoda T, Lathrop GM, Sekine A, Yamada R, Takahashi A, Ohnishi Y, Tanaka T, Nakamura Y (2004) Variation of gene-based SNPs and linkage disequilibrium patterns in the human genome. Hum Mol Genet 13:1623-1632

Vyse TJ, Kotzin BL (1998) Genetic susceptibility to systemic lupus Erythematosus. Annu Rev Immunol 16:261-292

Wick G, Hu Y, Schwarz S, Kroemer G (1993) Immunoendocrine communication via the hypothalamo-pituitary-adrenal axis in autoimmune diseases. Endocr Rev 14:539-563

Wilder RL (1996) Hormones and autoimmunity: animal models of arthritis. Baillieres Clin Rheumatol 10:259-271

Yamada H, Watanabe A, Mimori A, Nakano K, Takeuchi F, Matsuta $\mathrm{K}$, Tanimoto $\mathrm{K}$, Miyamoto $\mathrm{T}$, Yukiyama $\mathrm{Y}$, Tokunaga $\mathrm{K}$, Yokohari R (1990) Lack of gene deletion for complement C4A deficiency in Japanese patients with systemic lupus Erythematosus. J Rheumatol 17:1054-1057

Yamazaki K, McGovern D, Ragoussis J, Paolucci M, Butler H, Jewell D, Cardon L, Takazoe M, Tanaka T, Ichimori T, Saito S, Sekine A, Iida A, Takahashi A, Tsunoda T, Lathrop M, Nakamura Y (2005) Single nucleotide polymorphisms in TNFSF15 confer susceptibility to Crohn's disease. Hum Mol Genet 14:3499-3506

Yang Y, Chung EK, Zhou B, Lhotta K, Hebert LA, Birmingham DJ, Rovin BH, Yu CY (2004) The intricate role of complement component $\mathrm{C} 4$ in human systemic lupus erythematosus. Curr Dir Autoimmun 7:98-132 